\title{
The Role of Diagnostic Selective Nerve Root Blocks in the Management of Spinal Pain
}

\author{
Curtis W. Slipman, MD* and Zacharia Issac, MD**
}

Biochemical mechanisms to explain pain generation began relatively recently. Evaluating pain originating from the spine can be challenging because no historical or physical examination findings are sufficiently sensitive or specific for identifying each of the myriad of potential pain generators. These discrete anatomic structures include the nerve root, disc annulus, posterior longitudinal ligament, sacroiliac joint, and facet joint.

The diagnostic selective nerve root block is a useful test to determine the etiology of pain when other testing is inconclusive. If a patient with radicular symptoms has noncorroborative visual anatomic and neurophysiologic testing, diagnostic selective nerve root block may elucidate the level of pain generation. Also, in a patient with multiple abnormalities on visual anatomic testing, the lesion of clini- cal significance can be identified. However, this test may not be necessary in the patient when the specific radiculopathy level diagnosis is apparent; this is the case when a characteristic history and physical examination have a corroborative single-level imaging lesion. Determining which level is generating symptoms has implications for subsequent physical therapy, therapeutic injections, and surgery.

This review of selective nerve root blocks describes the relevant anatomy, pathophysiology, rationale, clinical utility, and complications.

Keywords: Spinal pain, selective nerve root blocks, transforaminal epidural injections, disc, facet joint, sacroiliac joint

locations of pain referral by axial structures (54-63). Even radicular involvement can be confusing, as its symptoms do not necessarily refer to classic dermatomal patterns (64). The evaluative tools may not offer definitive clues, as current imaging technology often demonstrates asymptomatic degenerative changes (65-68). Conversely, radicular pain may be present in the absence of imaging abnormalities consequent to local trauma $(69,70)$ or chemical irritation of the nerve root $(2,3)$. When electrodiagnostic testing is equivocal or negative, diagnostic selective nerve root blocks can be used.

The diagnostic selective nerve root block is a useful test to determine the etiology of pain when other testing is inconclusive $(38,71,72)$. Visual anatomic imaging may refer to plain radiography, computed tomography, magnetic resonance imaging, bone scan, single photon emission computed tomography, or other imaging studies that are helpful in defining anatomy. Neurophysiologic studies may refer to electromyography, nerve conduction studies, or somatosensory-evoked potentials. The diagnostic selective nerve root block is an example of a functional test. If a patient with radicular symptoms has noncorroborative visual anatomic and neurophysiologic testing, diagnostic selective nerve root block may elucidate the level of pain 
generation. Also, in a patient with multiple abnormalities on visual anatomic testing, the lesion of clinical significance can be identified. However, this test may not be necessary in the patient when the specific radiculopathy level diagnosis is apparent; this is the case when a characteristic history and physical examination have a corroborative single-level imaging lesion. Determining which level is generating symptoms has implications for subsequent physical therapy, therapeutic injections, and surgery.

\section{HISTORICAL ASPECTS}

Steindler and Luck recognized the potential value of analgesic and provocative injections as early as 1938 (73). MacNab and colleagues, in 1971, evaluated the value of diagnostic selective nerve root blocks in the preoperative evaluation of patients with nondiagnostic imaging studies and radicular symptoms (74). Selective nerve root blocks can be used to diagnose the etiology of radicular symptoms when imaging studies show multiple nerve root compression (75-87). In certain instances they can have predictive value. Derby et al (86) correlated surgical outcome with pain relief following transforaminal epidural steroid injections. Patients with symptoms of at least 1 year's duration, who had sustained relief from epidural injections, had dramatically better surgical outcomes than those individuals who failed to experience a steroid effect.

\section{ANATOMIC CONSIDERATIONS}

\section{Lumbosacral}

The five lumbar vertebrae are comprised of a vertebral body anteriorly, pedicles, laminae, and a spinous process which form the neural arch. The pedicle gives rise to the superior articular facet superomedially and the transverse processes laterally. The inferior facet arises from the laminae inferolaterally. On oblique view, the neural foramen is bounded superiorly by the pedicle, anteriorly by the vertebral body and intervertebral disc, inferiorly by the pedicle of the vertebrae below, and posteriorly by the superior articular facet of the inferior vertebra.

The lumbar neural foramen averages 18 to $28 \mathrm{~mm}$ in height and 7 to $12 \mathrm{~mm}$ in width. The dorsal root ganglion is 4 to $7 \mathrm{~mm}$ in diameter and usually resides at or medial to the midpoint of the interpedicular line. In some instances the dorsal root ganglion can be found intraspinally, medial to the neural foramen (88). The dural sleeve ends at the dorsal root ganglion; therefore, during diagnostic selective nerve root block, the needle tip can penetrate the lateral foramen at its superior margin with minimal risk of dural puncture, provided the midpoint of the pedicle represents the furthest medial point to which the needle is advanced.

The epiradicular and intertransverse membranes coalesce to cover the lateral aspect of the neural foramen and provide a palpable loss of resistance once pierced. Specifically, the epiradicular membrane lies outside a given nerve root and follows the course of the root proximally to the thecal sac and distally to the ventral ramus, hence confining injectate to the root in question.

In addition to the spinal nerve, other key neurologic structures traverse the foramen. Lateral to the foramen, the spinal nerve gives off a recurrent branch, the sinuvertebral nerve, which receives contributions from the sympathetic chain and then travels back through the foramen to innervate the posterior longitudinal ligament and the disc annulus at that level and one level above (89). The dura is additionally innervated at that level, one segment above and two segments below. These anatomic relationships can affect the specificity of diagnostic selective nerve root blocks. Another important anatomic consideration is the furcal nerve. The furcal nerve is a separate nerve root with its own dorsal root ganglion. In $93 \%$ of cadavers it travels with the L4 root through the L4-5 neural foramen. In the minority of cases it has been demonstrated to travel with the L3 and L5 nerve roots at their respective levels. Upon exiting out of the neural foramen, these branch off to the lumbosacral trunk, femorals, or obturator nerves. When a furcal nerve is present, compression of a given nerve root may cause symptoms in unusual distribution. Selective nerve root block can still identify the level of pathology despite this anomalous innervation.

The key anatomic structures involved in the technique of diagnostic selective nerve root block include the ipsilateral iliac crest, transverse process, and the superior articular process of S1 and their spatial relationship to the L5 neural foramen. When performing a selective nerve root block from the oblique angle, the foramen is seen medial and ventral to the iliac crest and inferior to the transverse process. A triangular portal created by these structures serves as the entry point. On occasion these structures can block entry due to degenerative hyperostosis, disc space collapse, postsurgical alterations, anatomic anomalies, or transitional segmentation. Examples of these occurrences include patients with a high and wide iliac crest, a wide or downsloping transverse process, or hypertrophied L5-S1 facet joint. Modified techniques are necessary to enter the foramen when these variations are present. 
The sacrum consists of five fused vertebral bodies forming a solid, triangular structure with four pairs of ventral and dorsal foramen. The S1-4 ventral and dorsal primary rami pass through these foramen. Of these, the $\mathrm{S} 1$ foramen is the most clinically relevant, as the S1 nerve root is vulnerable to compression or chemical irritation from the L5-S1 intervertebral disc or can be compressed by the S1 articular process (subarticular stenosis). The S1 foramen is located inferior and lateral to an imaginary interpedicular column connecting the L5 and S1 pedicles. Its dorsal foramen has a depth of $10 \mathrm{~mm}$. It is approached from a superolateral angle as the foramen itself slopes from lateral to medial and slightly superior to inferior. This approach is altered in instances of a narrow sacrum or a transitional segment.

\section{Thoracic}

The 12 thoracic vertebrae are characteristic for their costal facets that articulate with the ribs. An articulation occurs between the rib and vertebral body, costovertebral joint, and the rib and transverse process, costotransverse joint. Each thoracic nerve root exits at the level of its respective pedicle. It then gives rise to an intercostal nerve, which initially travels within a groove along the ventral and inferior aspect of its respective rib. After a short distance it courses caudally to reside in the midintercostal space (90). Diagnostic or therapeutic injections at thoracic levels are technically challenging due to the presence of the ribs and the close proximity to the lungs.

\section{Cervical}

Cervical selective nerve root blocks are commonly performed at C4-8 so anatomic discussion will be focused on these levels. Each cervical vertebra from C3-7 consists of a vertebral body anteriorly and a neural arch comprised of pedicles, laminae, and spinous process. The transverse process arises from the pedicle. It is broad and grooved in the cervical region. Each cervical transverse process has a transverse foramen through which the vertebral arteries pass as they course from the subclavian artery to the brain. Since the vertebral artery is located anteriorly and just lateral to the neural foramen, it can be inadvertently punctured.

The cervical neural foramen is bounded by the vertebral body and intervertebral disc anteriorly, the pedicle superiorly, the zygapophyseal joint posteriorly, and the pedicle and transverse process of the level below inferiorly. The cervical nerve root from the foramen above travels along the depression on the transverse process of the level be- low. When seen from a lateral oblique view, the most cephalad cervical foramen is that of $\mathrm{C} 3$. The $\mathrm{C} 3$ nerve root travels under the $\mathrm{C} 2$ pedicle, the $\mathrm{C} 4$ nerve root under the $\mathrm{C} 3$ pedicle and so on until the $\mathrm{C} 8$ nerve root emerges under the $\mathrm{C} 7$ pedicle.

\section{PATHOPHYSIOLOGY}

The underlying precept supporting the use of therapeutic injections in painful disorders of the spine hinges on the injectate's ability to decrease an inflammatory process, suppress neuronal transmission, or both. There have been numerous studies demonstrating a biochemical inflammatory process mediating pain in radiculopathy. Saal and colleagues (4) found elevated phospholipase $A_{2}$ in disk material obtained from patients treated surgically for radiculopathy. Phospholipase $\mathrm{A}_{2}$ is the rate limiting step in the arachidonic acid pathway, which subsequently generates prostaglandins and leukotrienes (6). Prostaglandin $\mathrm{E}_{2}$ has been shown to be elevated in disc material at the time of surgery, and it has been shown to play a role in sensitizing nociceptors to bradykinins (7). Additionally, Phospholipase $A_{2}$ has been shown to be neurotoxic (5). In work by Takahashi et al (8), disc material obtained during surgery in humans was assayed and cultured. They studied disc protrusion, extrusion, and sequestration and found that with disc protrusion there was an increased number of chondrocytes; whereas with extrusion and sequestration, there were an increased number of histiocytes, fibroblasts, and endothelial cells with relatively few chondrocytes. Cytokines are expressed by these cells and there is no apparent difference in the groups of cytokines produced when comparing disc protrusion, extrusion, or sequestration. Betamethasone added to the cell cultures of disc materials inhibited cytokine and Prostaglandin $\mathrm{E}_{2}$ production. In a study by Doita et al (9), disc samples obtained from surgical patients with an extrusion or sequestration showed increased granulation tissue and increased monocytes expressing interleukin-1. Interleukin-1 is known to stimulate inflammatory mediators and proteolytic enzymes including plasminogen activator, collagenase, and stromelysis. Kang and associates (10) assayed and compared disc tissue from patients being operated on for scoliosis and a herniated disc. They observed elevated levels of matrix metalloproteinase, nitric oxide, prostaglandin $\mathrm{E}_{2}$, and interleukin- 6 in the herniated disc group. Concentrations of interleukin-1, tumor necrosis factor and interleukin1 receptor antagonist protein were not appreciably increased or different in either group (10). Matrix metalloproteinase-3, inhibitor of matrix metalloproteinase1 , calcitonin gene-related peptide, vasoactive intestinal 
peptide, and substance $\mathrm{P}$ have all been associated with disc degeneration (11-15). It has been postulated that these inflammatory mediators play a role in radicular low back pain. Immune responses to nucleus pulposus in the vascular space has been theorized to be a mechanism of chronic inflammation. Work by Gertzbein (91) demonstrated significant elevation in the lymphocyte transformation test, a measure of the cellular immune response. IgM titers are also increased in two of three patients with discogenic back pain or sciatica (92).

The pathophysiology of neurogenic claudication is not known. Impairment of vascular and/or CSF flow has been hypothesized. Porter (93) proposed that neurogenic claudication arises from venous pooling, with a resultant decreased blood flow. Impaired flow leads to a metabolite buildup and nutrient-deficient state, creating nerve dysfunction (93). Ambulation increases venous return to the pelvic veins, with subsequent engorgement in Batson's plexus, and increases arterial perfusion; and the erect posture increases epidural pressure. In a study by Olmarker et al (94), methylglucose was injected into the CSF and its uptake into the cauda equina at various degrees of compression was studied. They found that, when compared to sham compression, even low pressures decreased transport of methylglucose to the nerve root. In another study, Olmarker et al (95) looked at venous flow impairment and compressive pressures. They found that two levels needed to be involved for a reduction in venous blood flow. These studies do not account for asymptomatic individuals with anatomic abnormalities, or the clinical response to selective nerve root blocks or epidural corticosteroids (96). Further delineation of biochemical mechanisms is needed to gain further understanding of this process.

The suppression of neuronal transmission is a key mechanism by which local anesthetics achieve their clinical effect. The axoplasmic membrane is a phospholipid bilayer, interspersed with glycolipids and cholesterol, with a hydrophobic outer layer and a hydrophilic inner layer. Numerous proteins are interspersed along the bilayer, which form pores that allow the preferential transport of sodium or potassium. While potassium is the main electrolyte responsible for the resting membrane potential of $-70 \mathrm{mV}$, sodium influx with depolarization is responsible for the action potential. In myelinated neurons, myelin is formed by Schwann cells that envelope and insulate the nerve fibers. Nodes of Ranvier are interruptions in the myelination, which facilitate saltatory conduction by having an increased concentration of sodium channels, while potassium channels are interspersed between nodes along the axon. In unmyelinated axons, there is an equal distribution of sodium and potassium channels. Pain is transmitted via thinly myelinated A delta fibers as well as unmyelinated $\mathrm{C}$ fibers. A delta fibers conduct at 5 to 30 meters per second, are commonly found in the skin, and are activated by sharp pricking pain, noxious heat, and mechanical stimuli. In contrast, $\mathrm{C}$ fibers conduct at 0.5-2 meters per second and are stimulated by high-intensity mechanical, chemical, and thermal stimuli. Pain is found in both peripheral and deep tissue. The propagation of the action potential is responsible for impulse transmission.

Local anesthetics are used for their ability to inhibit the propagation of the action potential. They alter the function of the sodium channels. These alterations result in a higher threshold for depolarization and a decrease in amplitude of the action potential and the rate of rise, as well as conduction velocity is diminished (97). Numerous other factors affect the onset and duration of effect of local anesthetics. There is a direct correlation between the onset of action and the lipid solubility of the local anesthetic. An anesthetic that is lipophilic and nonionic at the neural $\mathrm{pH}$ of 7.4 will most easily enter the axon. Increased protein-binding capacity of the anesthetic prolongs the duration of its action.

Researchers have reported on the anti-inflammatory properties of anesthetic agents. Possible mechanisms include inhibiting phagocytosis, decreasing phagocyte oxygen consumption, reducing polymorphonucleocyte lysosomal enzyme release, decreasing superoxide anion production, and reversibly inhibiting granulocyte adherence (98-107). Another theorized mechanism for the therapeutic effect of local anesthetic is the restoration of blood flow. Yabuki et al (108), using an animal model, found that anesthetic agents impeded normal radicular blood flow, while simultaneously increasing intraradicular flow. If the basis of the pain is diminished blood flow, as has been hypothesized in spinal stenosis and herniated nucleus pulposus, then directed injection of local anesthetics may be therapeutic (109-111). Indeed, some investigators have suggested that the therapeutic effect may be mediated by the inhibition of sympathetic output $(112,113)$.

Central processing theories have also been postulated to explain the therapeutic effect of local anesthetics. This theory suggests that a painful engram has been established in the brain, or repetitively firing nerves of the wide dynamic type have been triggered in the spinal cord (114). Anesthetic agents may cause a temporary block of this pain cycle. Finally, the response may be unrelated to physi- 
ologic effects of local anesthetic agents, as it has been demonstrated that a third of patients will respond to placebo alone $(115,116)$.

\section{RATIONALE}

Diagnostic injections are performed to confirm or exclude a clinically suspected pain generator. According to Steindler and Luck (73), if a structure is the etiology of the pain, stimulating it will provoke the pain while anesthetizing it will alleviate the pain. For this approach to have sufficient specificity, one must be able to selectively anesthetize a given structure, while not affecting nearby structures. With diagnostic selective nerve root block, there are numerous structures in close proximity that could result in a high false-positive block rate if improper technique is used. The value of using precise technique cannot be overemphasized since the sensitivity and specificity of diagnostic selective nerve root blocks will dramatically alter the quality of information obtained. Diagnostic selective nerve root block is typically performed in a patient with persistent pain when history, examination, imaging, and electrophysiologic testing do not clarify the pain generator. In other words, prior to employing this technique, it is a requirement that the information obtained will alter the treatment plan. Diagnostic selective nerve root block may be done as part of a diagnostic and therapeutic algorithm in the course of a patient's nonsurgical care. Alternatively, it may be performed presurgically to define the anatomic lesion that is contributing to a patient's pain.

\section{CLINICAL UTILITY}

The sensitivity of diagnostic selective nerve root block ranges from $87 \%$ to $100 \%(75,76)$. In 1973 Schutz et al (75) reported finding a corroborative lesion at the time of surgery in $87 \%$ of patients with a positive diagnostic block. Krempen et al (76) reported $100 \%$ surgical confirmation following a positive block. The specificity of diagnostic selective nerve root block ranges from $94 \%$ to $100 \%$ (81, $84,87)$. Dooley et al $(81)$ reported 3 out of 51 blocks to be false-positive, providing a specificity of $94 \%$. In 1990, Stanley et al reported 95\% specificity. VanAkkerveeken's prospective study (87) in 1993, conducted on patients with single-level root pathology, found the specificity of selective nerve root block to be $95 \%$.

Since the advent of MRI, with its highly sensitive imaging technology, adding specificity to the diagnostic workup has been paramount. Diagnostic selective nerve root block can be an effective technique in evaluating patients with multilevel pathology to ascertain which is the pain generator. Similarly it useful when the location of symptoms seems to conflict with abnormalities identified with imaging findings. White (117), in 1983, supported the use of diagnostic selective nerve root block as a pre-surgical test in patients with equivocal anatomic findings. He pointed out that it is more diagnostically precise than a caudal or interlaminar epidural. Herron (83), in 1989, reviewed his experience with diagnostic SNRB. He found the procedure useful in identifying previously undocumented disc herniations, the symptomatic level in multidisc herniation, the primary pain generator in the "spine hip syndrome," previously undocumented root irritation in spondylolisthesis, the symptomatic level in multilevel stenosis, and the symptomatic root in patients with documented postoperative fibrosis.

\section{OUTCOMES}

The diagnostic selective nerve root block adds efficiency and accuracy to the diagnostic and treatment algorithm. As stated previously, the ultimate goal of the diagnostic selective nerve root block is to identify a definitive pain generator. Uncovering the exact diagnosis will necessarily allow for diagnosis and specific treatment. Whether the treatment regimen consists of physical therapy, therapeutic injections, surgery or spinal cord stimulator placement, defining the diagnosis is the "rate-limiting step." Another, albeit not well recognized, benefit of obtaining a specific diagnosis is that it allows the patient to glean an understanding of the basis of his/her pain complaints. Such information can be comforting, thereby adding to the clinician's therapeutic intervention. When used as part of presurgical management, the diagnostic selective nerve root block may be able to focus the location of the operative procedure and minimize the number of levels operated upon. In those instances, there is a tremendous cost savings in terms of surgical cost, length of acute-care hospitalization and rehabilitation, and time before return to work. To date, there are no prospective, controlled trials with inclusion of a cost analysis to document outcomes.

\section{COMPLICATIONS}

Major complications of epidural and selective nerve root blocks have been reported in the literature. These include cardiac arrest, seizure, infection, nerve root trauma with permanent injury, intravascular injection, perforation of viscus or vascular structures, broken needle, and death. Spinal headache associated with dural puncture is possible with the transforaminal technique, but is less likely to oc- 
cur when compared with the interlaminar approach. While performing a selective nerve root block, it is important for the needle tip not to pass the interpedicular column on the posterior anterior view. At this level, the dorsal root ganglion and termination of the dural sleeve occur. Injections in the cervical region pose a hazard of spinal cord injury or vertebral artery trauma. In the thoracic region, the possibility of pneumothorax exists. A prospective analysis of the complication rate demonstrated no major complications following the performance of 350 consecutive cervical, thoracic, and lumbosacral selective nerve root blocks $(118,119)$. These researchers did observe that minor complications such as temporary aggravation of patient symptoms, soreness at the site of injection, headache, and vasovagal response to injection were more common than compared to a control group. However, accidental dural puncture, subdural injection, neural trauma, injection to the spinal cord, and hematoma formation have been described following epidural injections. Spinal cord trauma or spinal cord or epidural hematoma formation is a catastrophic complication rarely seen following interventional procedures in the cervical spine, thoracic spine, or upper lumbar spine (120-128). Thus, it has been suggested that interventional pain procedures be performed with placement of a needle only in an awake patient (121-125). However, unfortunately, it has been reported that even an awake patient may not be able to detect spinal cord puncture (129). Infectious complications include epidural abscess and bacterial meningitis, even though no such complications have been reported following selective nerve root blocks. Other complications include inadvertent subdural injection of local anesthetic and steroids $(130,131)$, development of complex regional pain syndrome (132) and retinal hemorrhages (133), and subdural intracranial air $(134,135)$ reported following epidural injections; however, these are unlikely following selective nerve root blocks. Intravascular injection, intraneural injection, and neural trauma are described as potential complications following selective nerve root blocks $(38,136,137)$. Incidence of intravascular penetration and placement of the needle with transforaminal epidural injections have been described as significant.

Absolute contraindications for the procedure include spinal infection, bacteremia, local cellulitis or ulceration at the injection site, and uncontrolled coagulopathy. Relative contraindications include anticoagulant therapy and contrast allergy. For patients on warfarin, if permitted by the patient's internist, the patient is withdrawn from warfarin at least 3 days prior to the procedure. Warfarin can be safely resumed the day after the procedure. Patients with contrast allergies are premedicated with a regimen involving administration of $50 \mathrm{mg}$ of prednisone 24 hours, 12 hours, and 1 hour prior to the procedure; $50 \mathrm{mg}$ of diphenhydramine is also given 1 hour prior to the procedure.

\section{INDICATIONS}

The diagnostic selective nerve root block is indicated in a patient with persistent radicular pain of unknown etiology. Several scenarios exist in which it may be helpful diagnostically:

- In identifying an inflamed nerve root in a patient with a history of radicular pain when results of visual anatomic studies and neurophysiologic studies are not corroborative; and In identifying the pain generator when patients have multiple abnormalities on visual anatomic studies.

\section{TECHNICAL CONSIDERATIONS}

A structured process should be implemented for the performance of diagnostic blocks, with delineation of the purpose and the process of the procedure. Immediate assessment is important because, as time passes, patient memory of pain intensity is unreliable (119). More importantly, patients have to frequently perform provocative maneuvers to definitely judge the outcome of the diagnostic selective nerve root block. Patients are not equipped to do this without the aide of trained medical professionals. Patients also need to be reinformed about what to expect postprocedure. For example, patients may experience postinjection pain from the intramuscular course of the needle. If they obtain pain relief, they may also begin to increase their activity, which may exacerbate radicular symptoms after the local anesthetic effect has dissipated. Greater than $80 \%$ reduction on the pre- and postinjection visual analogue or verbal pain-rating scale is considered as a positive response. However, thresholds as low as 50\% (86) or as high as $90 \%$ have been reported(17).

\section{Lumbosacral Diagnostic Selective Nerve Root Block}

The patient is positioned prone on the fluoroscopy table. The fluoroscopy tube is rotated to achieve an oblique view of the vertebral column, hence allowing visualization of the intervertebral foramen. The pedicle is a key anatomic landmark. At the proper degree of rotation, the pedicle will appear elongated and its outline will blend with the 
transverse process. The medial margin of the superior articular facet joint of the vertebral body below will align with the medial lateral to mid of the inferior aspect of the superior pedicle. In this position, the intervertebral foramen can be seen clearly bounded anteriorly by the vertebral body, superiorly by the pedicle, and posteriorly by the facet joint. A metal surgical clamp is then laid on the skin to identify the target point for needle advancement, the six-o'clock position just inferior to the pedicle. A skin wheal is made with local anesthetic at this location, and a 3.5-inch, 20- to 22-gauge spinal needle is inserted parallel to the fluoroscopy beam. The needle tip is advanced under fluoroscopic guidance to the target site. Ideally, the needle and tip are not visible since they are viewed on end. The hub with its radiopaque center is visible overlying the target site during advancement. The needle is advanced until its tip is beneath the pedicle. Novices may intentionally contact the inferior border of the pedicle to identify proper depth before redirecting the needle tip to lie beneath the pedicle. At this point the needle is released, and the fluoroscopy tube is rotated back to the posterior-anterior (PA) position, where the needle tip should appear immediately lateral to the midline of the spherically shaped pedicle. The tip is advanced under fluoroscopic guidance to the six-o' clock position on this PA view. A palpable loss of resistance is felt by the clinician as the needle tip pierces the epiradicular membrane. Contrast is injected to confirm position, and no more than $1.0 \mathrm{~mL}$ of local anesthetic is used to avoid anesthetizing the sinuvertebral nerve or adjacent structures.

For obese patients, a two-needle technique is used because the 3.5-inch needle will not have sufficient length to reach the target. The first needle used is a 3.5-inch, 18- or 20gauge needle advanced until the needle hub reaches the skin. After the stylet is removed, a 5- to 8-inch, 22- or 25gauge spinal needle is inserted using the first needle as a guide. The second needle is advanced until an increase in tissue resistance is perceived, usually 2 to $4 \mathrm{~mm}$ lateral to the respective pedicle.

Difficulty reaching the target area arises from starting too superior or inferior to the transverse process. If the entrance point is too cephalad, the needle tip will strike the transverse process before reaching the foramen. If the skin is entered too caudally, the flare of the inferior aspect of the vertebral body will be encountered before reaching the foramen. In either of these scenarios, the needle must be withdrawn and repositioned. Attempting to redirect the needle will result in repeated bony obstruction.
Unique technical difficulties may arise in the performance of an L5 selective nerve root block. Technical difficulties may arise in patients with a high and wide iliac crest, a wide or downsloping transverse process, hypertrophied L5 S1 facet joint, collapsed disc space, L5 S1 fusion, or spondylolisthesis. Modified techniques may be necessary to enter the foramen in these instances. A single needle technique using a PA or only slightly oblique projection can be used. The skin wheal is raised just lateral to the medial border of the iliac crest and just inferior to the L5 transverse process. The needle is inserted at an oblique angle until it contacts the most medial edge of the iliac crest. The iliac crest is anesthetized with a small amount of anesthetic, and the needle is advanced ventrally using the crest to deflect the needle medially toward the foramen.

A two-needle technique can be used if the superior articular process blocks entry into the foramen. A gentle curve is created to the second needle prior to introducing it into the guide needle. The guide is slightly withdrawn and the second needle is advanced just beyond the level of the guide. While holding the second needle stationary, the guide needle is withdrawn. The second needle is advanced to the target location. With this technique, the clinician should be careful not to advance the needle too far in a ventral direction, or risk iliac artery or peritoneal entry.

$\mathrm{S} 1$ selective nerve root block is done with the patient in the prone position and a PA projection of the fluoroscopy tube. The needle enters the foramen parallel to the foraminal canal. The needle tip is advanced parallel to the $\mathrm{x}$-ray beam, targeting the lateral edge of the foramen, until the periosteum is contacted. The needle is slightly withdrawn and then advanced into the foramen. After a palpable loss of resistance is felt as the needle tip pierces the epiradicular membrane, contrast is injected to confirm epidural flow and to rule out intravascular injection. One milliliter of local anesthetic is injected.

\section{Thoracic Diagnostic Selective Nerve Root Block}

The patient is positioned prone with the arms either raised above the head and crossed or at the side. The latter is used if a c-arm is used, the former if using a myelography table or if the patient is particularly muscular. An oblique view is obtained such that the pedicle never crosses the midpoint of its respective vertebral body. Local anesthetic is injected and a skin wheal is made inferior to the pedicle. A 22- or 25-gauge, 3.5-inch needle is advanced until the 
inferior aspect of the rib is reached. The needle is then repositioned in a 10-20 degree cephalocaudal direction. It can then be advanced to the neural foramen under fluoroscopic guidance in the PA view. Specific guidelines for diagnostic injections at the thoracic level have not been published. In general, we use $1 \mathrm{~mL}$ of $2 \%$ lidocaine unless epidural flow is observed, in which case $0.5 \mathrm{~mL}$ of lidocaine is instilled. This is done to minimize the likelihood that adjacent structures will be anesthetized.

Two major technical issues must be raised. If the needle is inserted too laterally, the needle will enter the pleural cavity, so it is best to err on too medial a starting point. Secondly, if performing a left upper thoracic selective nerve root block, if the needle is advanced too ventrally the aorta could be entered. If one is uncertain that the needle will stay in the safe zone while advancing toward the pedicle, a diagnostic medial intercostal nerve block will provide the same information.

\section{Cervical Diagnostic Selective Nerve Root Block}

The patient lies supine on the fluoroscopy table. The patient's entire trunk is rotated as a unit, creating an oblique view to the anterior-posterior (AP)-oriented x-ray beam. Supportive bolsters and cushions are placed under the shoulders and upper back to maintain proper positioning. The orientation of the cervical nerve roots and the transverse processes upon which they travel are more anterior in the upper cervical vertebrae and more lateral in the lower cervical vertebrae. Hence, the upper cervical vertebrae require a body position closer to AP, while a more lateral position is necessary for performing lower cervical root blocks. The patient's head is rotated toward the contralateral shoulder and supportive pillows are placed under the occiput. To ensure proper positioning, the superior articular process should be distinctly visible at the most lateral portion of the neural foramen. The patient is anesthetized with local anesthetic, and the skin wheal should be just lateral to the base of the superior articular process. A 1.5-inch, 22-gauge spinal needle is incrementally advanced under fluoroscopic guidance until the base of the articular process is reached. The nerve roots exit at the caudal portion of the foramen, so this location is targeted by the needle tip. Three steps are subsequently performed: the needle is slightly withdrawn; the needle tip is oriented to a more medial location by directing the hub dorsally; and, finally, the needle tip is advanced 1 to $2 \mathrm{~mm}$. Dural puncture can be avoided by limiting advancement to $2 \mathrm{~mm}$, except for the C3 selective nerve root block in women, where neural foraminal depth can be as little as $1 \mathrm{~mm}$ (138).
Contrast is injected to confirm position. In general, we use 0.8 to $1.0 \mathrm{~mL}$ of $2 \%$ lidocaine hydrochloride (Xylocaine ${ }^{\circledR}$ ) for the cervical selective nerve root block; however specific guidelines regarding injection volumes have not been established.

Selective nerve root block in the cervical spine may also be performed in the prone position rotating the head to the opposite side with positioning of the c-arm appropriately to open the foramen; however, the authors prefer the supine position.

\section{CONTROVERSIES}

Because of the proximity of the nerve root to other key structures, there exists the possibility of anesthetizing structures other than what the clinician believes he or she is anesthetizing. The furcal nerve, sinuvertebral nerve, adjacent nerve roots, or medial branch of the dorsal primary ramus or the facet joint may be anesthetized inadvertently. We use a maximum of $1.0 \mathrm{~mL}$ of anesthetic solution for the lumbar spine, $0.5 \mathrm{~mL}$ to $1.0 \mathrm{~mL}$ for the thoracic spine and $0.5 \mathrm{~mL}$ to $1.0 \mathrm{~mL}$ for the cervical spine. If too much solution is used, an increased false positive rate and decreased specificity will occur. North et al (139) found the diagnostic selective nerve root block to lack specificity; however they used a 3.0-mL injectate, which may have contributed to their high false-positive rate. If too little anesthetic is used, one may not block impulse transmission and diagnostic block may not be achieved, thus increasing the false-negative rate and decreasing the sensitivity. Prospective studies to determine the ideal quantities of solution that should be used are necessary.

The diagnostic selective nerve root block is a key part of a diagnostic algorithm in the workup of a patient with radicular pain. It can define the target of subsequent therapeutic injections. In the pre-surgical patient it may be able to limit the extent of surgery that a patient requires and also increase the success of surgical outcome by better identifying the painful lesion. This however, is controversial because no prospective, controlled, randomized trial has been performed to assess the overall beneficial effects on outcome.

\section{CONCLUSION}

The diagnostic selective nerve root block, when performed by experienced spine physicians, is a safe and effective diagnostic tool. It can be used as a part of the diagnostic algorithm in the management of radicular pain when 
noninvasive measures have failed to provide a diagnosis. It can be used in conjunction with therapeutic selective nerve root blocks with a goal of lasting pain relief or as part of presurgical evaluation in the patient with multiple abnormalities on imaging or noncorroborative imaging. More research is needed on the impact of diagnostic selective nerve root blocks on clinical outcomes.

\section{REFERENCES}

1. Mixter WJ, Barr JS. Rupture of the intervertebral disc with involvement of the spinal canal. $N$ Engl J Med 1934; 211:210-215.

2. Hasue M. Pain and the nerve root: An interdisciplinary approach. Spine 1993; 18:2053-2058.

3. Saal JS. The role of inflammation in lumbar pain. Spine 1995; 20:1821-1827.

4. Saal JS, Franson RC, Dobrow R et al. High levels of inflammatory phospholipase A2 activity in lumbar disc herniations. Spine 1990; 15:674-678.

5. Ozaktay AC, Cavanaugh JM, Blagoev DC et al. Phospholipase $\mathrm{A}_{2}$ induced electrophysiologic and histologic changes in rabbit dorsal lumbar spine tissues. Spine 1995; 20:2659-2668.

6. Franson RC, Saal JS, Saal JA. Human disc phospholipase $\mathrm{A}_{2}$ is inflammatory. Spine 1992; 17:S129-132.

7. Wilburger RE, Wittenberg RH. Prostaglandin release from lumbar disc and facet joint tissue. Spine 1994; 19:2068-2070.

8. Takahashi H, Suguro T, Okazima Y et al. Inflammatory cytokines in the herniated disc of the lumbar spine. Spine 1996; 21:218-224.

9. Doita M, Kanatanni T, Harada $\mathrm{T}$ et al. Immunohistologic study of the ruptured intervertebral disc of the lumbar spine. Spine 1996; 21:235-241.

10. Kang JD, Gergescu HI, McIntyre-Larkin L et al. Herniated lumbar intervertebral discs spontaneously produce matrix metalloproteinases, nitric oxide, interleukin-6, and prostaglandin $\mathrm{E}_{2}$. Spine 1996; 21:271-277.

11. Kanemoto M, Hukuda S, Komiya Y et al. Immunohistochemical study of metalloproteinase-3 and tissue inhibitor of metalloproteinase- 1 in human intervertebral discs. Spine 1996; 21:1-8.

12. Ashton IK, Roberts S, Jaffray DC et al. Neuropeptides in the human intervertebral disc. J Orthop Res 1994; 12:186-192.

13. Konniten YT, Gronblad M, Antti-Poika I et al. Neuroimmunohistochemical analysis of periodical nociceptive neural elements. Spine 1990; 15: 383-386.

14. Cornefjord M, Olmarker K, Farley DB et al. Neuropeptide changes in compressed spinal nerve roots. Spine 1995; 20:670-673.

15. Weinstein J, Claverie W, Gibson S. The pain of dis- cography. Spine 1988; 13:1344-1348.

16. Schwarzer AC, Aprill CN, Derby R et al. The prevalence and clinical features of internal disc disruption in patients with chronic low back pain. Spine 1995; 20:1878-1883.

17. Dreyfuss P, Michaelson M, Pauza K, et al. The value of medical history and physical examination in diagnosing sacroiliac joint pain. Spine 1996; 21: 25942602.

18. Maigne J, Aivaliklis A, Pfefer F. Results of sacroiliac joint double block and value of sacroiliac pain provocation tests in 54 patients with low back pain. Spine 1996; 21:1889-1892.

19. Slipman CW, Sterenfeld EB, Chou LH et al. The value of radionuclide imaging in the diagnosis of sacroiliac joint syndrome. Spine 1996; 19:2251-2254.

20. Schwarzer, AC, Aprill CN, Bogduk N. The sacroiliac joint in chronic low back pain. Spine 1995; 20:31-37.

21. Dreyfuss P. Dreyer S, Griffin J et al. Positive sacroiliac screening tests in asymptomatic adults. Spine 1994; 19:1138-1143.

22. Manchikanti L, Singh V, Kloth D et al. Interventional techniques in the management of chronic pain: Part. 2.0. Practice Guidelines. Pain Physician 2001; 4:2496.

23. Manchikanti L, Pampati VS, Fellows B et al. Prevalence of lumbar facet joint pain in chronic low back pain. Pain Physician 1999; 2:59-64.

24. Manchikanti L, Pampati VS, Bakhit CE et al. The diagnostic validity and therapeutic value of lumbar facet joint nerve blocks with or without adjuvant agents. Cur Rev Pain 2000; 4:337-344.

25. Manchikanti L, Pampati V, Fellows B et al. The inability of the clinical picture to characterize pain from facet joints. Pain Physician 2000; 3:158-166.

26. Bogduk N. International Spinal Injection Society guidelines for the performance of spinal injection procedures. Part 1: Zygapophyseal joint blocks. Clin J Pain 1997; 13:285-302.

27. Manchikanti L. Facet joint pain and the role of neural blockade in its management. Cur Rev Pain 1999; 3:348-358.

28. Schwarzer AC, Derby R, Aprill CN et al. The value of the provocation response in lumbar zygapophysial joint injections. Clin J Pain 1994; 10:309-313.

29. Schwarzer AC, Derby R, Aprill CN et al. Pain from the lumbar zygapophysial joints: A test of two models. J Spinal Disord 1994; 7:331-336.

30. Schwarzer AC, Aprill CN, Derby R et al. Clinical features of patients with pain stemming from the lumbar zygapophysial joints. Is the lumbar facet syndrome a clinical entity? Spine 1994; 19:1132-1137.

31. Schwarzer AC, Wang S, Bogduk N et al. Prevalence and clinical features of lumbar zygapophysial joint pain: A study in an Australian population with chronic low back pain. Am Rheum Dis 1995; 54:100-106. 
32. Schwarzer AC, Aprill CN, Derby R et al. The relative contributions of the disc and zygapophyseal joint in chronic low back pain. Spine 1994; 19:801-806.

33. Bigos SJ, Boyer OR, Braen GR et al. Acute Low Back Problems in Adults. Clinical Practice Guideline Number 4. AHCPR Publication No. 95-0642. Agency for Health Care Policy and Research, Public Health Service, US Department of Health and Human Services, Rockville, MD, December 1994.

34. Spitzer WO, Leblanc FE, Dupuis M (eds). Quebec Task Force on Spinal Disorders. Scientific approach to the assessment and management of activity-related spinal disorders: A monograph for clinicians. Spine 1987; (suppl) 12:1-59.

35. Spitzer WO, Skovron ML, Salmi LR et al. Scientific monograph of the Quebec Task Force on whiplashassociated disorders: Redefining "whiplash" and its management. Spine 1995; (Suppl) 20:1-73.

36. Manchikanti L. The role of neural blockade in the management of chronic low back pain. Pain Digest 1999; 9:166-181.

37. Manchikanti L. Neural blockade in cervical pain syndromes. Pain Physician 1999; 2:65-84.

38. Manchikanti L. Transforaminal lumbar epidural steroid injections. Pain Physician 2000; 3:374-398.

39. Kellegren JH. On the distribution of pain arising from deep somatic structures with charts of segmental pain. Clin Sci 1939; 3:35-46.

40. Hirsch D, Inglemark B, Miller M. The anatomical basis for low back pain. Acta Orthop Scand 1963; 33:1.

41. Kuslich SD, Ulstrom CL, Michael CJ. The tissue origin of low back pain and sciatica: A report of pain response to tissue stimulation during operation on the lumbar spine using local anesthesia. Orthop Clin North Am 1991; 22:181-187.

42. Bogduk N, Aprill C. On the nature of neck pain, discography, and cervical zygapophyseal joint blocks. Pain 1993; 54:213-217.

43. Bogduk N. Musculoskeletal pain: Toward precision diagnosis. Progress in pain research and management. In Jensen TS, Turner JA, Wiesenfeld-Hallin Z (eds). Proceedings of the 8th World Congress on Pain. IASP Press, Seattle, 1997, pp 507-525.

44. Bogduk N, Simons DG. Neck pain: Joint pain or trigger points. In: H Vaeroy and J Merskey J (eds). Progress in Fibromyalgia and Myofascial Pain. Amsterdam, Elsevier, 1993, pp 267-273.

45. Barnsley L, Lord SM, Wallis BJ et al. The prevalence of chronic cervical zygapophyseal joint pain after whiplash. Spine 1995; 20:20-26.

46. Lord SM, Barnsley L, Wallis BJ et al. Chronic cervical zygapophysial joint pain with whiplash: A placebocontrolled prevalence study. Spine 1996; 21:17371745.

47. Waddell G, Turk DC. Clinical assessment of low back pain. In Turk DC, Melzack R (eds). Handbook of Pain
Assessment. First Edition. The Guilford Press, New York, 1992, pp 15-36.

48. Deyo RA, Rainville J, Kent DL. What can the history and physical examination tell us about low back pain? JAMA 1992; 268:760-765.

49. Haldeman S. Failure of the pathological model to predict back pain. Spine 1990; 15:718-732.

50. Schwarzer AC, Scott AM, Wang SC et al. The role of bone scintigraphy in chronic low back pain: A comparison of SPECT and planar images and zygapophysial joint injection. Aust NZJ Med 1992; 22:185.

51. Schwarzer AC, Wang SC, O'Driscoll D et al. The ability of computed tomography to identify a painful zygapophysial joint in patients with chronic low back pain. Spine 1995; 20:907-912.

52. Deyo RA. Fads in the treatment of low back pain. $N$ Engl J Med 1991; 325:1039-1040.

53. Slipman CW, Whyte II W, Chow D et al. Sacroiliac joint syndrome. Pain Physician 2001; 4:143-152.

54. Slipman CW. Jackson HB, Lipetz JS et al. Sacroiliac joint pain referral zones. Arch Phys Med Rehab 2000; 81:334-8.

55. Fukui S, Ohseto K, Shiotani M et al. Distribution of referred pain from the lumbar zygapophyseal joints and dorsal rami. Clin J Pain 1997; 13:303-307.

56. Dreyfuss P, Tibiletti C, Dreyer SJ. Thoracic zygapophyseal joint pain patterns. A study in normal volunteers. Spine 1994; 19:807-811.

57. Mooney V, Robertson J. The facet syndrome. Clin Ortho Related Res 1976; 115:149-56.

58. McCall IW, Park WM, O'Brien JP. Induced pain referral from posterior elements in normal subjects. Spine 1979; 4:441-446.

59. Marks R. Distribution of pain provoked from lumbar facet joints and related structures during diagnostic spinal infiltration. Pain 1989; 39:37-40.

60. Fukui S, Ohseto K, Shiotani M et al. Referred pain distribution of the cervical zygapophyseal joints and cervical dorsal rami. Pain 1996; 68:79-83.

61. Dwyer A, Aprill C, Bogduk N. Cervical zygapophyseal joint pain patterns: A study in normal volunteers. Spine 1990; 6:453-457.

62. Aprill C, Dwyer A, Bogduk N. The prevalence of cervical zygapophyseal joint pain patterns II: A clinical evaluation. Spine 1990; 6:458-461.

63. Bogduk N, Marsland A. The cervical zygapophyseal joints as a source of neck pain. Spine 1988; 13:610617.

64. Slipman CW, Plastaras C, Palmitier RA et al. Symptom provocation of fluoroscopically guided cervical nerve root stimulation: Are dynatomal maps identical to dermatomal maps? Spine 1998; 23:2235-2242.

65. Hitselberger WE, Witten RM. Abnormal myelograms in asymptomatic patients. J Neurosurgery 1968; 28:204-206. 
66. Jensen MC, Brant-Zawadzki MN, Obuchowaski N et al. Magnetic resonance imaging of the lumbar spine in people without back pain. $N$ Engl J Med 1994; 2: 69-73.

67. Wiesel SW, Tsourmas N, Feffer HL et al. A study of computer assisted tomography. The incidence of positive CAT scans in an asymptomatic group of patients. Spine 1984; 8:549-551.

68. Boden SD, Davis DO, Dina TS et al. Abnormal MRI in asymptomatic subjects. J Bone Joint Surg Am 1990; 72 A(3):403-408

69. Slipman CW, Lipetz JS, Jackson HB et al. Outcomes of therapeutic selective nerve root blocks for whiplash induced cervical radicular pain. Pain Physician 2001; 4:167-174.

70. Bertrand G. The "battered" root problem. Orthop Clin North Am 1975; 6:305-310.

71. O'Neill C, Derby R, Kenderes L. Precision injection techniques for diagnosis and treatment of lumbar disc disease. Seminars in Spine Surgery 1999; 11:104-118.

72. Slipman CW. Diagnostic nerve root blocks. In Gonzalez EG, Materson RS (eds). The Nonsurgical Management of Acute Low Back Pain. Demos Vermande, New York 1997, pp 115-122.

73. Steindler A, Luck JV. Differential diagnosis of pain in the low back: Allocation of the source of the pain by the procaine hydrochloride method. JAMA 1938; 110:106-113.

74. Macnab I. Negative disc exploration: An analysis of the causes of nerve root involvement in sixty-eight patient. J Bone Joint Surg (AM) 1971; 53A:58915903.

75. Schutz H, Loughweed WM, Wortzman G et al. Intervertebral nerve-root in the investigation of chronic lumbar disc disease. Can J Surg 1973; 16:217-221.

76. Krempen JF, Smith BS. Nerve root injection: A method for evaluating the etiology of sciatica. $J$ Bone Joint Surg (AM) 1974; 56A: 1435-1444.

77. Tajima T, Furukawa K, Kuramochi E. Selective Lumbosacral radiculography and block. Spine; 1:68-77.

78. Hoppenstein R. A new approach to the failed back syndrome. Spine 1980; 5:371-379.

79. Kikuchi S, Hasue M, Nishiyama K. Anatomic and clinical studies of radicular symptoms. Spine 1984; 9:2330 .

80. Haueisen DC, Smith BS, Myers SR et al. The diagnostic accuracy of spinal nerve injection studies. Clin Orthop Rel Res 1985; 198:179-183.

81. Dooley JF, McBroom RJ, Taguchi T et al. Nerve root infiltration in the diagnosis of radicular pain. Spine 1988; 13:79-83.

82. Porzelius J. Memory for pain after nerve-block injections. Clin J Pain 1995; 11:112-120.

83. Herron LD. Selective nerve root block in patient selection for lumbar surgery: Surgical results. J Spinal Disord 1989; 2:75-79.
84. Stanley D, McLaren MI, Euinton HA et al. A prospective study of nerve root infiltration in the diagnosis of sciatica: A comparison with radiculogaphy, computed tomography, and operative findings. Spine 1990; 6:540-543.

85. Castro WH, van Akkerveeken PF. der diagn ostische Wert der lumbalen Nervenwurzelblockde. A Orthop Ihre Grenzgeb 1991; 129:376-379.

86. Derby R, Kine G, Saal JA et al. Response to steroid and duration of radicular pain as predictors of surgical outcome. Spine 1992; 17 (Suppl):176-183.

87. Van Akkerveeken PF. The diagnostic value of nerve sheath infiltration. Acta Orthop San 1993; 64:61-63.

88. Hasegawa T, Mikawa Y, Watanabe R. Morphometric analysis of the lumbosacral nerve roots and dorsal root ganglia by magnetic resonance imaging. Spine 1996; 21:1005-1009.

89. Bogduk N. The anatomical basis for spinal pain syndromes. J Manipulative Physiol Ther 1995; 18:603605

90. Moore KL. The Thorax. In Satterfield T, Napora L, Lumpkin K et al (eds). Clinically Oriented Anatomy. Third edition. Williams and Wilkins. Baltimore, 1992, p 55.

91. Gertzbein SD. Degenerative disk disease of the lumbar spine. Clin Orthop Rel Res 1977; 129:68-71.

92. Marshall LL, Trethewie ER, Curtain CC. Chemical radiculitis. Clin Orthop Rel Res 1977; 129:61-67.

93. Porter RW. Spinal stenosis and neurogenic claudication. Spine 1996; 21:2046-2052.

94. Olmarker K, Rydevik B, Hansson T et al. Compressioninduced changes of the nutritional supply to the porcine cauda equina. J Spinal Disord 1990; 3:25-29.

95. Olmarker K, Holm S, Rydevik B. Single versus double level nerve root compression: an experimental study on the porcine cauda equina with analysis of nerve impulse conduction properties. Clin Orthop 1992; 6:35-39.

96. Ciocon JO, Galindo-Ciocon D, Amaranath L et al. Caudal epidural blocks for elderly patients with lumbar canal stenosis. JAGS 1994; 42:593-596.

97. Raymond SA, Strichartz GR. Further comments on the failure of impulse propagation in nerves marginally blocked by local anesthetics. Anesth Analg 1990; 70:121.

98. Cullen BF, Haschke RH. Local anesthetic inhibition of phagocytosis and metabolism of human leukocytes. Anesthesiology 1974; 40:142.

99. Hoidal JR, White JG, Repine JE. Influence of cationic local anesthetics on the metabolism and ultrastructure of human alveolar macrophages. J Lab Clin Med 1979; 93:857.

100. Goldstein IM, Lind S, Hoffstein S et al. Influence of local anesthetics upon human polymorphonuclear leukocyte function in vitro. J Exp Med 1977; 146:483494. 
101. MacGregor RR, Thorner RE, Wright DM. Lidocaine inhibits granulocyte adherence and prevents granulocyte delivery to inflammatory sites. Blood 1980; 56:203-209.

102. Cassuto J, Nellgard P, Stage L. Amide local anesthetics reduce albumin extravasation in burn injuries. $A n-$ esthesiology 1990; 72:302-307.

103. Peck SL, Johnston RB, Horwitz LD. Reduced neutrophil superoxide anion release after prolonged infusions of lidocaine. J Pharmacol Exp Ther 1985; 235:418422.

104. Rimback G, Cassuto J, Wallin G et al. Inhibition of peritonitis by amide local anesthetics. Anesthesiology 1988; 69:881-886.

105. Martinsson T, Haegerstrand A, Dalsgaard C. Ropivacaine and lidocaine inhibit proliferation of nontransformed cultured adult human fibroblasts, endothelial cells and keratinocytes. Agents Actions 1993; 40:78-85.

106. Ohsaka A, Saionji D, Sato N et al. Local anesthetic lidocaine inhibits the effect of granuloctye colony stimulating factor on human neutrophil functions. Exp Hematol 1994; 22:460-466.

107. Ramus GV, Cesano L, Barbalonga A. Different concentrations of local anesthetics have different modes of action on human lymphocytes. Agents Actions 1983; 13:333-341.

108. Yabuki S, Kikuchi S. Nerve root infiltration and sympathetic block. Spine 1995; 20:901-906.

109. Olmarker K, Rydevik B, Holm S, Bagge U. Effects of experimental graded compression on blood flow in spinal nerve roots. A vital microscopic study on the porcine cauda equina. J Orthop Res 1989; 7:817-823.

110. Takahashi K, Olmarker K, Holm S et al. Double level cauda equina compression: An experimental study with continuous monitoring of intraneural blood flow in the porcine cauda equina. J Ortho Res 1993; 11:104-109.

111. Yabuki S, Kikuchi S, Olmarker K. Acute effects of nucleus pulposus on blood flow and endoneurial fluid pressure in rat dorsal root ganglia. Spine 1998; 23:2517-2523.

112. Winne AP, Hartman JT, Myers HL Jr et al. Pain Clinic II: Intradural and extradural corticosteroids for sciatica. Anesth Analg Curr Res 1972; 51:990-1003.

113. El Mahdi MA, Abdel Latif FY, Janko M. The spinal nerve root "innervation" and a new concept of the clinico-pathological interrelations in back pain and sciatica. Neurochirurgia 1981; 24:137-141.

114. Raj PP. Prognostic and therapeutic local anesthetic blockade. In Cousins MJ, Bridenbaugh PO (eds). Neural Blockade. Lippincott, Philadelphia, 1988, p 899.

115. Beecher HK. The powerful placebo. JAMA 1955; 159:1602.

116. Benson H, Epstein MD. The placebo effect. A neglected asset in the care of patients. JAMA 1975; 232:1225.
117. White A. Injection techniques for the diagnosis and treatment of low back pain. Orthop Clin N Am 1983; 14: 553-567.

118. Slipman CW, Meyers JS, Chou LH et al. Complications of fluoroscopically guided spinal injections. Arch Phys Med Rehab 1995; 76:1032.

119. Huston CW, Slipman CW, Meyers JS et al. Side effects and complications of fluoroscopically guided nerve root injections. Arch Phys Med Rehab 1996; 77:937.

120. Benzon HT, Molly RE. Outcomes, efficacy, and compliances from management of low back pain. In Raj PP, Abrams BM, Benzon HT et al (eds). Practical Management of Pain. Third Edition, Mosby, Philadelphia 2000, pp 891-903.

121. Bromage RP, Benumof JL. Paraplegia following intracord injection during attempted epidural anesthesia under general anesthesia. Reg Anesth Pain Med 1998; 23:104-107.

122. Krane EJ, Dalens BJ, Murat I, et al. The safety of epidurals during general anesthesia. Reg Anesth Pain Med 1998; 23:433-438.

123. Hodges SD, Castleberg RL, Miller T et al. Cervical epidural steroid injection with intrinsic spinal cord damage. Two case reports. Spine 1998; 23:2137-2142.

124. Derby R. Cervical epidural steroid injection with intrinsic spinal cord damage. Point of view. Spine 1998; 23:2141-2142.

125. Manchikanti L. Epidural steroid injections and intrinsic spinal cord damage. Spine 1999; 24:1170-1171.

126. Williams KN, Jackowski A, Evans PJ. Epidural haematoma requiring surgical decompression following repeated cervical epidural steroid injections for chronic pain. Pain 1990; 42:197-199.

127. Benzon HT, Wong HY, Siddiqui $\mathrm{T}$ et al. Caution in performing epidural injections in patients on several antiplatelet drugs. Anesthesiology 1999; 91:15581559.

128. Horlocker TT, Wedel DJ, Offord KP. Does preoperative antiplatelet therapy increase the risk of hemorrhagic complications associated with regional anesthesia? Anesth Analg 1990; 70:631-634.

129. Pounder D, Elliott S. An awake patient may not detect spinal cord puncture. Anaesthesia 2000; 55:194.

130. Lubenow T, Keh-Wong E, Kristof K et al. Inadvertent subdural injection: A complication of an epidural block. Anesth Analg 1988; 67:175-179.

131. Lehmann LJ, Pallares VS. Subdural injection of a local anesthetic with steroids: Complication of epidural anesthesia. South Med J 1995; 88:467-469.

132. Siegfried RN. Development of complex regional pain syndrome after a cervical epidural steroid injection. Anesthesiology 1997; 86:1394-1396.

133. Ling C, Atkinson PL, Munton CGF. Bilateral retinal hemorrhages following epidural injection. $\mathrm{Br} J$ Ophthalmol 1993; 77:316. 
134. Katz JA, Lukin R, Bridenbaugh PO et al. Subdural intracranial air: An unusual cause of headache after epidural steroid injection. Anesthesiology 1991; 74:615.

135. Mateo E, Lopez-Alarcon MD, Moliner S et al. Epidural and subarachnoid pneumocephalus after epidural technique. Eur J Anesethsiol 1999; 16:413-17.

136. Sullivan WJ, Willick Se, Chira-Adisai W et al. Incidence of intravascular uptake in lumbar spinal injection procedures. Spine 2000; 25:481-486.

137. Furman MB, O’Brien EM, Zgleszewski TM. Incidence of intravascular penetration in transforaminal lumbosacral epidural steroid injections. Spine 2000; 25:2628-2632.

138. Ebraheim NA, an HS, Xu R et al. The quantitative anatomy of the cervical nerve root groove and the intervertebral foramen. Spine 1996; 21:1619-1623.

139. North RB. Kidd DH. Zahurak M et al. Specificity of diagnostic nerve blocks: A prospective, randomized study of sciatica due to lumbosacral spine disease. Pain 1996; 65:77-85. 